\title{
O "Conteúdo Básico Comum": uma análise linguística da Proposta Curricular de Minas Gerais
}

Catarine Caum

Tatiana Galieta

\section{Resumo}

O Novo Plano Curricular do Ensino Médio do Estado de Minas Gerais inclui a produção, distribuição e adoção de materiais didáticos e outros destinados ao trabalho pedagógico do professor para as diversas disciplinas que compõem o currículo escolar. Neste artigo, realizamos uma análise linguística do Conteúdo Básico Comum de Física que privilegia aspectos relacionados à caracterização de seus materiais como um gênero de texto didático. Para tanto, são investigadas categorias como os relatos (classificação e composição), experimentos, as explicações, biografias, narrativas e exposições; além de estruturas textuais como as recapitulações e metáforas. Os resultados da análise revelam algumas opções dos autores, bem como determinadas ausências, que acabam por compor um texto cujas características linguísticas se semelham as do livro didático, sobretudo os módulos didáticos.

Palavras-chave: Conteúdo Básico Comum, Proposta Curricular de Minas Gerais, ensino de Física, análise linguística.

\section{Abstract}

The "Common Basic Contents": a linguistic analysis of the Curricular Proposal of Minas Gerais.

The New High School Curriculum Plan of the State of Minas Gerais includes the production, distribution and adoption of textbooks and other materials for the educational work of the teacher for the various disciplines that make up the curriculum. In this article, we conducted a linguistic analysis of the Common Basic Contents of physics that emphasizes aspects related to the characterization of their materials as a genre of didactic text. Therefore, some categories are investigated: reports (classification and composition), experiments, explanations, biographies, narratives and exhibitions, in addition to textual structures as recaps and metaphors. The analysis results reveal some authors' options as well as certain absences which eventually compose a text whose characteristics resemble the language of the textbook, especially the educational modules. 
Keywords: Common Basic Contents, Curricular Proposal of Minas Gerais, physics education, linguistic analysis.

\section{Introdução}

O Conteúdo Básico Comum (CBC) constitui-se na proposta curricular desenvolvida no ano de 2005 pela Secretaria de Educação do Estado de Minas Gerais (SEE-MG) voltada para as escolas da rede pública mineira. A principal justificativa da SEE-MG para a elaboração dessa nova proposta é a de que o ensino tradicional estaria desgastado e ultrapassado no que diz respeito aos seus conteúdos e suas abordagens, uma vez que os assuntos têm sido tratados de forma demasiadamente abstrata, exaustiva e completamente fora da realidade dos alunos, não contemplando sua criatividade, imaginação e senso crítico frente ao conhecimento científico. Nesse sentido, o CBC da disciplina escolar Física apresenta uma proposta diferenciada que se materializa nos textos de seus módulos didáticos, nas suas orientações pedagógicas, nos seus roteiros de atividades, bem como na própria Proposta Curricular de Física. O presente artigo busca compreender a composição linguística do CBC caracterizando-o como um gênero de texto específico a partir da análise de categorias como os relatos, as narrativas, as recapitulações e as metáforas. Em trabalhos anteriores complementamos este tipo de investigação linguística por meio de elementos da análise retórica composicional e crítica do CBC Física a qual nos permitiu compreender aspectos mais amplos da estrutura curricular e didática desse material específico das escolas públicas mineiras (CAUM, 2010; CAUM e NASCIMENTO, 2011).

O CBC Física ${ }^{1}$ tem como pretensão a busca pelo nivelamento de ensino das escolas integrantes da rede estadual e explora, essencialmente, o conceito Energia e a partir dele aborda os temas: conservação de energia, energia térmica, energia mecânica, calor e movimento, energia elétrica, calculando a energia elétrica e energia na Terra. Neste trabalho, focalizamos nossa análise nos textos referente ao tema Energia na Terra por considerarmos que ele pode se tornar particularmente relevante nas aulas de Física por suscitar diferentes interpretações e oferecer a possibilidade de trabalho interdisciplinar e contextualizado por meio de diversas abordagens.

\section{o Conteúdo Básico Comum (CBC)}

$1 \quad \mathrm{C} \quad \mathrm{CBC} \quad$ Física encontra-se disponível em http://crv.educacao.mg.gov.br/sistema_crv/index.aspx?id_projeto=27\&id objeto=68011\&tipo=ob\&cp=780 031\&cb=\&n1=\&n2=Proposta\%20Curricular\%20\%20CBC\&n3=Ensino\%20M\%C3\%A9dio\&n4=F\%C3\%ADsica\&b=s. 
No ano de 2004, a SEE-MG começou a implementar o Projeto Escolas-Referência com o objetivo de reconhecer e lidar com as diferenças existentes no sistema de ensino público mineiro, além de desenvolver projetos diferenciados para escolas com diversos problemas, desde aqueles de infra-estrutura até a falta de material didático. As escolas reconhecidas por seu trabalho realizado junto a sua comunidade deram início ao projeto o qual envolve atualmente ações de formação continuada dos professores e de aprofundamento de estudos de alunos do ensino médio visando a preparação para o vestibular, entre outras (SEE-MG, 2006)1. Já em 2005, as escolas-referência adotaram a primeira versão do $\mathrm{CBC}$ em turmas do $1^{\circ}$ ano do Ensino Médio (EM). De posse dos resultados dessa experiência, a SEE-MG lançou em 2006 o Novo Plano Curricular para o Ensino Médio com a intenção de que os materiais didáticos do CBC fossem adotados por todas as escolas mineiras. Em 2007 foi apresentada uma nova versão dos materiais, versão esta que investigamos em nossas análises dos conteúdos específicos de Física.

Abrangendo as disciplinas de Arte, Biologia, Educação Física, Física, Geografia, História, Inglês, Matemática, Português e Química, o CBC foi distribuído nas escolas estaduais de Minas Gerais, em 2007, já com as modificações incorporadas pelos professores das Escolas Referência os quais, desde o ano de 2005, acompanharam e avaliaram a implantação do material.

Dentre os materiais desenvolvidos para a disciplina Física, a Proposta Curricular de Física (PCF) constitui-se em um documento que foi elaborado para a apresentação do CBC com as habilidades a serem desenvolvidas e os temas a serem abordados no $1^{\circ}$ ano do EM. Além disso, são sugeridos os conteúdos para os demais anos do EM. Buscamos informações na PCF a respeito da estrutura do $\mathrm{CBC}$, pois foi nesse documento que julgamos encontrar os vestígios das influências motivadoras para a seleção dos conteúdos do CBC.

O CBC visa tornar o ensino de Física mais conceitual e com menos formulações matemáticas, tentando aproximar o cotidiano do aluno aos conhecimentos científicos necessários para construção de seu conhecimento (SEE-MG, 2007). Fortalecer a relação entre comunidade e escola e formar alunos bem preparados para atuar na sociedade também são outros dois objetivos que são propostos pelo CBC. Este último ponto vai ao encontro dos objetivos dos Parâmetros Curriculares Nacionais (PCNEM e PCN+), onde se supõe que o EM prepare "o jovem para ser capaz de lidar com situações reais, crises de energia, problemas ambientais, aparelhos, concepções do universo (...)" (BRASIL, 2002, p. 4).

Os documentos que compõem o $C B C$ também se encontram digitalizados em um suporte na Internet: a página do Centro de Referencia Virtual do Professor (CRV) da SEE-MG². No CRV

1 Outras informações sobre o Projeto Escolas-Referência estão disponíveis em https://www.educacao.mg.gov.br/webnve/index.php?option=com content\&task=view\&id=1343\&ltemid=5 $\underline{98}$.

${ }^{2}$ O sítio do CRV pode ser acessado pelo endereço: http://crv.educacao.mg.gov.br.

R. B. E. C. T., vol 5, núm. 3, set-dez.2012 ISSN - 1982-873X 
encontram-se versões atualizadas do $\mathrm{CBC}$ de todas as disciplinas, bem como as orientações didáticas ou pedagógicas, os roteiros de atividades, os módulos didáticos, fórum de discussões, experiências simuladas, vídeos educacionais e outras atividades. Alguns destes materiais são objetos da análise aqui apresentada e passam a ser caracterizados brevemente a seguir.

As orientações pedagógicas são guias para auxiliar o professor no ensino de cada tópico. Todas as orientações pedagógicas contêm os seguintes itens: por que ensinar, condições prévias para ensinar, o que ensinar, como ensinar, como avaliar e sugestões de leitura para o professor. Essas orientações foram criadas para orientar e nortear os professores no uso dos roteiros de atividades e os módulos didáticos.

Os roteiros de atividades trazem experiências simples a serem realizadas em sala de aula com o auxílio do professor. O material dos roteiros didáticos é voltado para o professor, mas as atividades são sugeridas ao aluno. Nos roteiros são apresentadas as habilidades a serem desenvolvidas, os pré-requisitos necessários para a execução da atividade, as descrições dos procedimentos sugeridos, as possíveis dificuldades encontradas pelos alunos durante a sua execução, um pequeno glossário e algumas questões a serem trabalhadas depois da atividade.

Os módulos didáticos consistem em sugestões de conteúdos distribuídos por aulas. Eles podem ser impressos e utilizados com os alunos diretamente. Ao final de cada módulo didático existem exercícios e perguntas com a finalidade de fixação dos conteúdos, semelhantes a capítulos de livros didáticos.

A seguir comentaremos como esses materiais estão organizados nos conteúdos específicos de Física.

\section{CBC Física}

A PCF é apresentada no documento CBC Física para o Ensino Médio (SEE-MG 2007). A nova versão da proposta é adequada às normas dispostas na resolução SEE-MG, n 833, de 24 de novembro de 2006 e contém os conteúdos principais propostos para o $1^{\circ}$ ano do $E M$, assim como os conteúdos complementares a serem aprofundados e as possibilidades de ampliação desses conteúdos ao longo das outras séries do EM. O documento esclarece que não pretende promover uma descrição dos conteúdos abordados no EM e que apenas aqueles que são considerados fundamentais para o aprendizado básico do aluno (e que, portanto, são indispensáveis seus estudos) são mais bem detalhados.

O CBC Física para o $1^{\circ}$ ano do EM apresenta os conteúdos estruturados em Eixos Temáticos que contêm uma listagem de habilidades que devem ser desenvolvidas referentes a conteúdos específicos. Os Eixos Temáticos I, II e III possuem conteúdos em torno do conceito de energia. A razão para esta escolha, segundo os autores do documento, é a concepção de que este conceito é fundamental para as ciências naturais e que a partir dele é possível ocorrer uma integração entre as disciplinas Física, Química e Biologia. Ademais, o conceito energia seria pré- 
requisito para o entendimento de uma grande quantidade de fenômenos naturais e acontecimentos cotidianos, os quais podem ser relacionados a questões sociais, ambientais e econômicas.

$\mathrm{O} C B C$ Física sugere que no $1^{\circ}$ ano do EM seja feita uma abordagem mais conceitual em torno dos fenômenos naturais a partir de sua observação e discussão; a ideia é partir de fenômenos simples para daí alcançar os mais complexos. Nas próximas séries do EM as abordagens ficam mais sofisticadas e elaboradas à medida que o tema for sendo trabalhado e interagindo com as demais disciplinas do currículo.

Neste trabalho focalizaremos o Eixo Temático I - Energia na Terra, que é composto por três tópicos:

1. Energia na vida humana, cuja habilidade pretendida é o reconhecimento pelo aluno da energia como algo indispensável para a vida na Terra.

2. O Sol e as fontes de energia, a partir da caracterização do Sol como a nossa principal fonte de energia, buscam-se identificar todas as possiveis fontes de energia e compreender o seu modo de obtenção.

3. Distribuição de energia na Terra, este tópico pretende desenvolver a habilidade de compreensão dos movimentos de rotação e translação da Terra e como as estações climáticas são influenciadas por estes, além de reconhecer que a distribuição energética do Sol não é uniforme em todo o planeta.

Justificamos nossa escolha pela análise linguística dos conteúdos presentes no Eixo Temático I - Energia na Terra por entendermos que este se constitui em um tema amplo que pode vir a despertar diferentes interpretações e oferecer a possibilidade de trabalho interdisciplinar e contextualizado por meio de diversas abordagens.

Os documentos analisados neste trabalho são: os módulos didáticos (MD1, MD2, MD3), as orientações pedagógicas (OP1, OP2, OP3) e os roteiros didáticos (RD1, RD2, RD3), por serem os três principais componentes do $C B C$ que são empregados direta ou indiretamente em sala de aula. Além disso, o próprio documento da PCF (SEE-MG, 2007) também compõe o corpus de análise pelo fato do mesmo compor o CBC Física e trazer justificativas para a seleção de conteúdos e abordagens.

\section{Referencial teórico: análise linguística}

Vários autores cujas pesquisas situam-se no referencial das teorias sociais do discurso consideram que o gênero de texto é algo que está relacionado à estabilidade estrutural e à prática social na qual ele se insere. Halliday e Hassan (1985), por exemplo, em sua análise semântica e 
gramatical de textos, estabelecem uma relação entre os diferentes tipos de textos e as diferentes atividades da vida social. Os autores percebem que os textos diferem em termos das estruturas linguísticas internas particulares e também estão relacionados aos contextos nos quais são produzidos e distribuídos, constituindo diferentes tipos ou gêneros de textos. Logo, os gêneros de textos apresentam padrões globais de organização textual e encontram-se relacionados a determinada prática social. Neste sentido, Gill e Whedbee (1997) entendem que qualquer texto encontra-se vinculado a um gênero específico. $O$ gênero é entendido com referência a um conjunto de textos que compartilham características discursivas específicas e estratégias argumentativas ou estilísticas similares.

Assumimos nesse trabalho que o corpus analisado constitui um gênero de texto particular uma vez que ele se encontra inserido na prática social de ensinar Ciências na escola e apresenta características discursivas próprias e estabilidade do ponto de vista organizacional e estilístico. Buscamos operacionalizar a análise por meio de categorias elaboradas por Halliday (1993) e Martin (1993). Estes autores consideram a questão do gênero de texto didático científico e identificam alguns de seus elementos característicos, os quais servem como um quadro de referência para a análise de textos pertencentes a este gênero.

Martin (1993) reconhece que a linguagem científica constitui importante peça tecnológica usada pelos cientistas. O autor argumenta que para ser letrado em ciências é necessário compreender essa linguagem técnica, ou seja, é fundamental entender as formas pelas quais os cientistas organizam seus conhecimentos em textos verbais escritos e imagéticos. Em consonância com as ideias de Halliday e Hasan (1985), Martin afirma que ao construir uma interpretação alternativa de mundo àquela presente no senso comum, a Ciência passa a documentar e a explorar o conhecimento acumulado através da produção de diferentes gêneros de textos. Neles, o mundo encontra-se organizado em termos de classificação, composição, diagramação, decomposição e definição de coisas (entidades) e processos científicos. Martin propõe ainda uma classificação de gêneros textuais científicos, dentre os quais se destacam: a exposição, a narrativa, o relato (que classifica, decompõe, descreve funções e lista propriedades), a explicação e a biografia.

Além disso, algumas estruturas textuais - como as recapitulações e as metáforas também caracterizam o gênero de texto científico escolar uma vez que ele também tem origem em sua constituição no discurso pedagógico (NASCIMENTO, 2003). No caso das recapitulações, de acordo com Mortimer e Scott (2002), elas teriam como principal função a manutenção da narrativa do ensino. Neste caso, os autores referem-se aos conceitos explorados nas salas de aula de Ciências ao longo do ano letivo. A partir desta consideração, entendemos que as recapitulações consistem em referências a contextos ou episódios anteriores àquele momento do discurso do professor ou do livro didático. Já Ogborn e cols. (1996), consideram que as narrativas são mantidas não apenas no nível conceitual mas também podem estar relacionadas a 
procedimentos do trabalho didático científico. Neste sentido, os autores comentam que a seleção das explicações entendidas como relevantes pelos professores e a ordem em que elas são tratadas na sala de aula são sempre funções de uma estrutura explicativa mais ampla. Com isso, o que está sendo explicado pelo professor em um determinado momento poderá estar relacionado a algo que já foi mencionado anteriormente ou a algo que ainda será explorado.

Já as metáforas são figuras de linguagem que possuem uma função mediadora exercendo um papel argumentativo e estético no discurso. Neste trabalho adotamos a definição de Lima (1984) que entende a metáfora como a "transferência de um termo para uma esfera de significação que não é a sua, em virtude de uma comparação implícita" (p. 461). No âmbito do ensino de ciências encontramos pesquisas que discutem possíveis vantagens ou problemas que o emprego de metáforas e analogias podem trazer para a aprendizagem de conceitos científicos. Independente da função que as metáforas desempenham no processo de ensino e aprendizagem das ciências, por observarmos sua recorrência em textos didáticos (reconhecida, inclusive, pelos avaliadores do Programa Nacional do Livro Didático, PNLD), buscamos identificar nos materiais do CBC Física algumas metáforas relacionadas ao tema Energia.

\section{Resultados}

Os materiais do CBC Física têm seus aspectos linguísticos analisados por meio de dois elementos centrais: as características que definem o seu gênero de texto e as estruturas que são constituidoras de sua composição textual. Buscamos a caracterização do CBC enquanto um gênero textual específico através da identificação de categorias como os relatos, as explicações, as biografias, os experimentos e as narrativas. Com relação ao segundo elemento, realizamos uma análise na qual investigamos as recapitulações e as metáforas que são as estruturas lingüísticas próprias do cotidiano e do discurso científico na escola.

\section{a) Características definidoras do Gênero de Texto}

Conforme mencionado anteriormente, o gênero de texto remete-se à prática social na qual ele se insere e materializa-se textualmente em formas estruturais estáveis (HALLIDAY, 1993; MARTIN, 1993). Dentre os diferentes textos que circulam na sala de aula de física encontramos os materiais do $C B C$ os quais se constituem, conforme as análises que se seguem, em um gênero de texto didático científico. Segundo Martin (1993) este gênero de texto caracteriza-se pela presença de relatos, explicações, exposições, biografias, experimentos e narrativas, as quais se constituem em categorias de análise que buscamos identificar no corpus composto por materiais do CBC. A primeira categoria que buscamos caracterizar são os relatos.

Os relatos têm a função de organizar as informações sobre os objetos e os processos sobre os objetos. Geralmente, os relatos são encontrados nas formas de classificações e composições, podendo ainda descrever funções e listar propriedades de entidades científicas. Os relatos na forma de classificação são aqueles períodos do texto em que termos técnicos são 
definidos e os processos são classificados em categorias, conforme destacado nos exemplos abaixo nos quais os autores definem a energia cinética, a energia potencial gravitacional (Ex.1) e a radiação eletromagnética (Ex. 2). Percebemos ao longo dos textos de MD1, MD2 e MD3 que os autores usam a função itálico para marcar os novos conceitos apresentados nos textos.

Ex. 1: Em Física distinguem-se vários tipos de energia, dois dos quais são a energia cinética e o outro a energia potencial gravitacional. A primeira refere-se ao produto $1 / 2 M v^{2}$, em que $M$ é a massa de um corpo que se move com a velocidade $v$; $a$ segunda designa o produto Mgh, no qual M é a massa de um corpo que se encontra à altura $h$ acima de um determinado nível de referência e $g$ é a aceleração adquirida por esse corpo se ele for solto e puder cair livremente. (MD1 - item 5)

Ex. 2: A energia que recebemos do Sol, chamada radiação solar, é emitida incessantemente por ele e sua natureza é a mesma da luz, das ondas de rádio, das radiações que utilizamos nos fornos de micro-ondas e na telefonia, entre outros dispositivos que fazem parte do nosso dia-a-dia. Esses são diversos tipos de radiação eletromagnética, que diferem uns dos outros por uma propriedade fundamental: a freqüência, que é o número de vibrações (ou ciclos) por segundo realizados em cada ciclo; por exemplo, a luz, ou radiação visível, tem freqüencia muito alta, de muitos bilhões de ciclos/s (em torno de $10^{15}$ ), enquanto a radiação das emissoras FM está na faixa de $10^{6}$ ciclos/s. (MD2- item 4)

Os relatos na forma de composições são aqueles nos quais as partes estão relacionadas ao todo, geralmente sendo apresentados por diagramas ou esquemas que identificam tais partes. A Figura 1, na qual os autores apresentam de maneira simplificada a estrutura da Terra, é um exemplo encontrado no MD2 de relato imagético na forma de composição. 


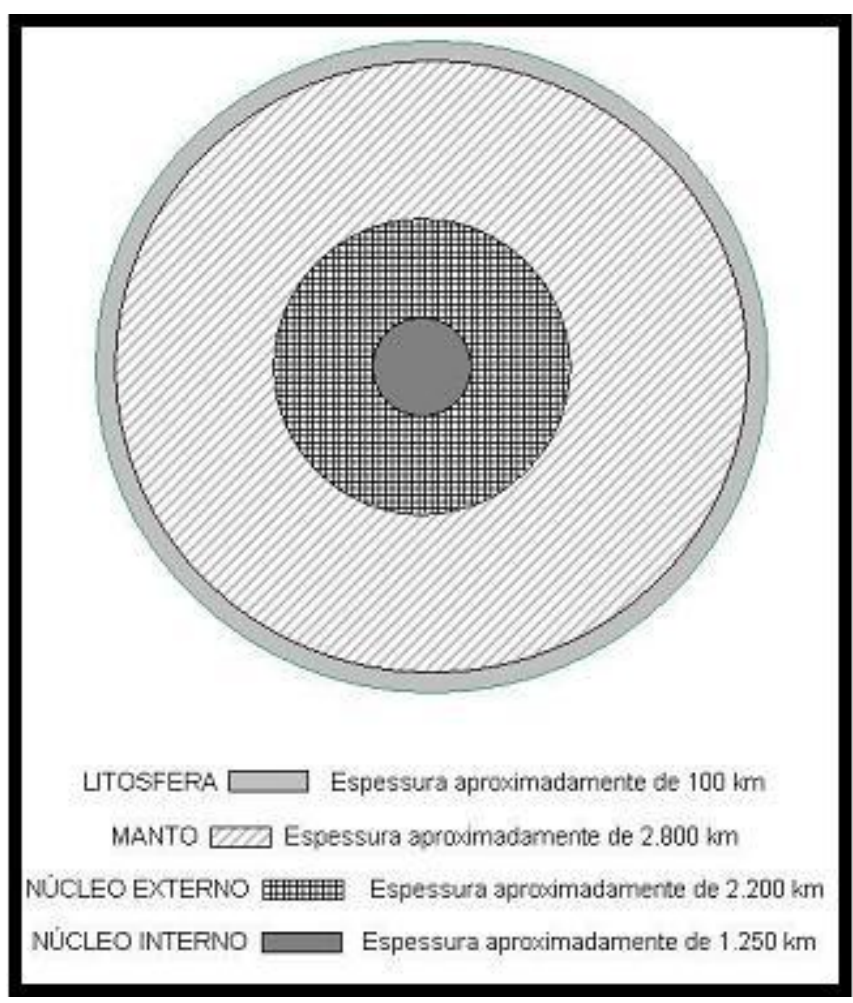

Figura 1: Exemplo de composição - estrutura da Terra (MD2)

Os relatos podem ainda ser escritos descrendo funções (ver Ex. 3) e também listando propriedades de entidades científicas (ver Exs. 4 e 5).

Ex. 3: Em cada segundo, 1 metro quadrado da superfície terrestre recebe a energia de $1.400 \mathrm{~J}=1,4 \mathrm{~kJ}$, que é denominada constante solar e será representada por b. (MD2 - item 4)

Ex. 4: (...) o petróleo e o carvão devem ser condenados, pois a queima desses combustíveis tem provocado crescente envenenamento da atmosfera terrestre, onde se acumulam várias substâncias nocivas, originadas dessa queima. Entre elas, duas são especialmente importantes: o anidrido carbônico ou dióxido de carbono (fórmula química: $\mathrm{CO}_{2}$ ) e o enxofre (símbolo químico: S). (MD1 - item 7)

Ex. 5: $O$ cociente $\mathrm{J} / \mathrm{s}$ (joule por segundo) aparece freqüentemente em Física, porque indica uma propriedade importante das máquinas, denominada potência; ele recebe um nome especial: watt e seu símbolo é $W ; 1.000$ watts $=1 \mathrm{~kW} .0$ valor de $B$ acima indicado pode então ser escrito abreviadamente como $6=1,4 \mathrm{k}(\mathrm{J} / \mathrm{s}) / \mathrm{m}^{2}=1,4$ $\mathrm{kW} / \mathrm{m}^{2}$. (MD2-item 4)

As explicações são compostas por exposições de processos científicos em etapas e se diferenciam dos relatos pelo maior número de ações interligadas em uma lógica sequencial ao longo da explicação. Explicações ainda podem ser construídas na forma de decomposição que geralmente são apresentados em diagramas ou esquemas. Na Figura 2 é apresentado um exemplo de explicação diagramática que traz a representação do funcionamento de uma usina de 
maré. Já a Figura 3 mostra uma explicação esquemática que está inserida no texto do CBC com fins didáticos, e não apenas ilustrativo, produzindo sentidos sobre o funcionamento de uma usina nuclear.

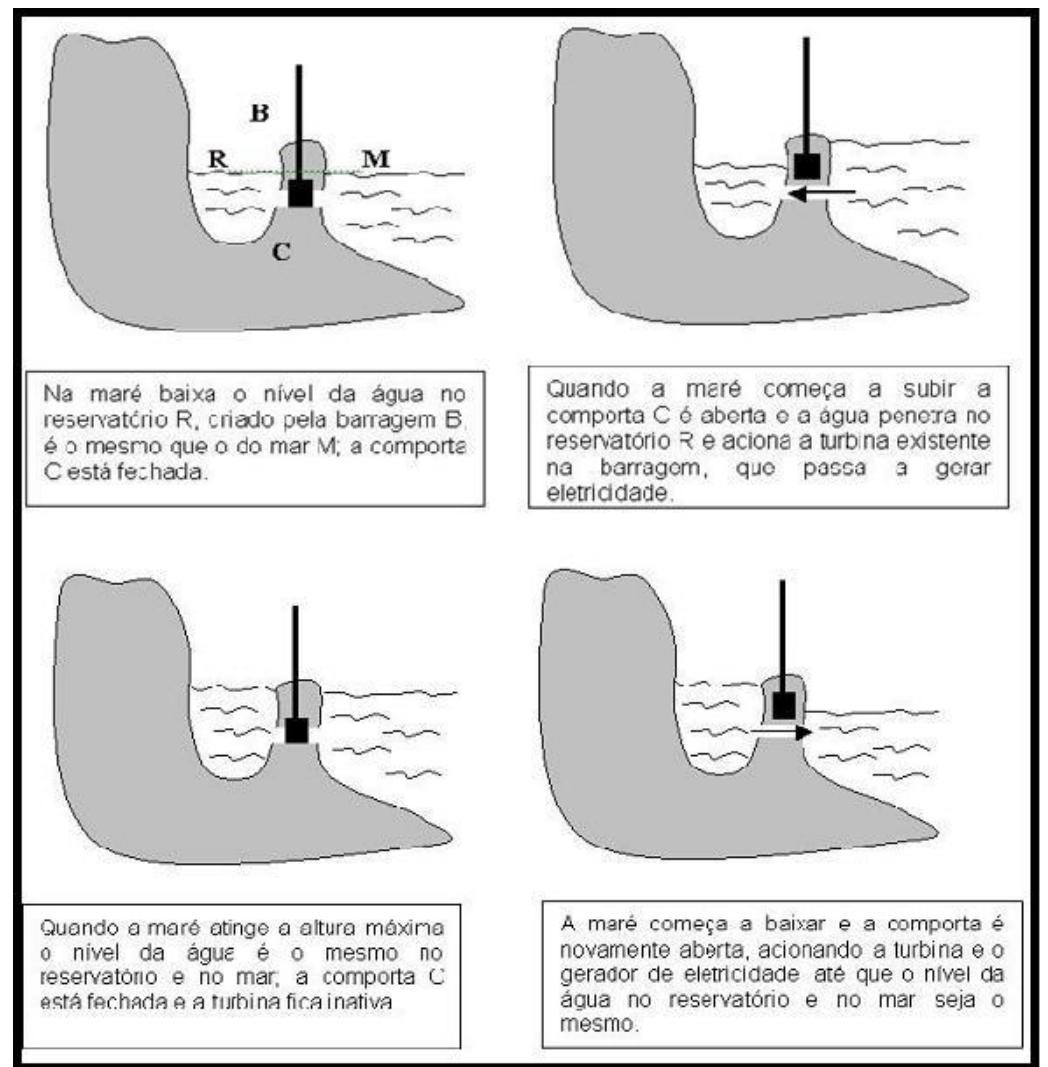

Figura 2: explicação em diagrama (funcionamento de uma usina de maré no MD2)

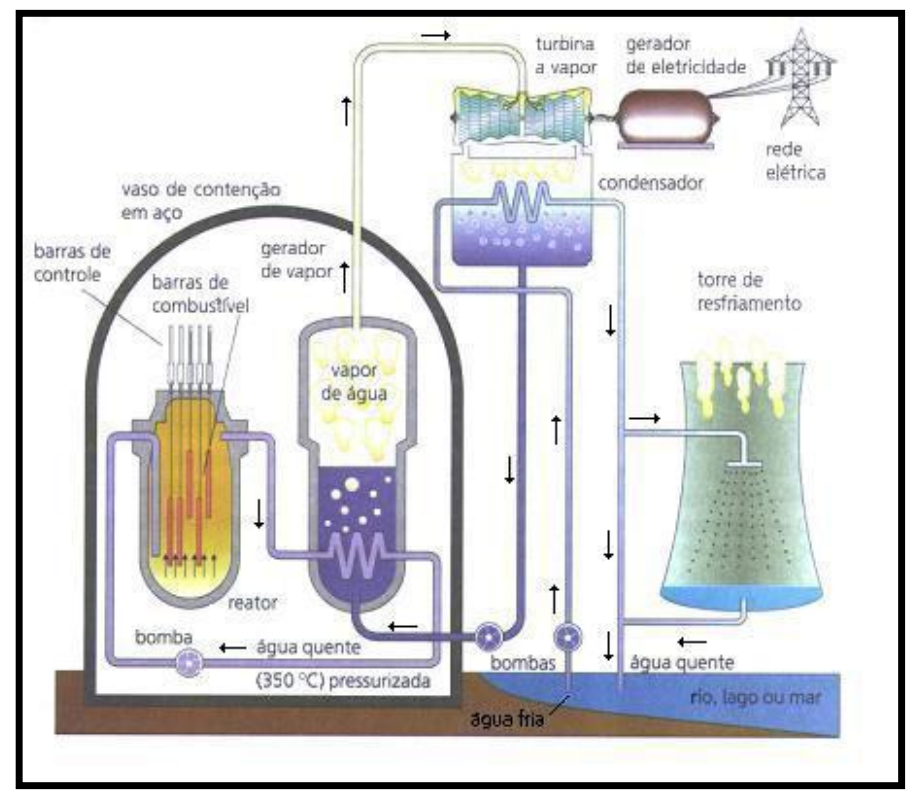

Figura 3: Esquema presente no MD2

Figura 3: esquema sobre funcionamento de usina nuclear (MD2) 
No MD3, encontramos outro exemplo de explicação imagética (Figura 4), na qual os autores representam um diagrama diferenciando as camadas da atmosfera terrestre, que junto ao texto escrito, permite aos leitores compreender a organização e a composição dessas camadas.

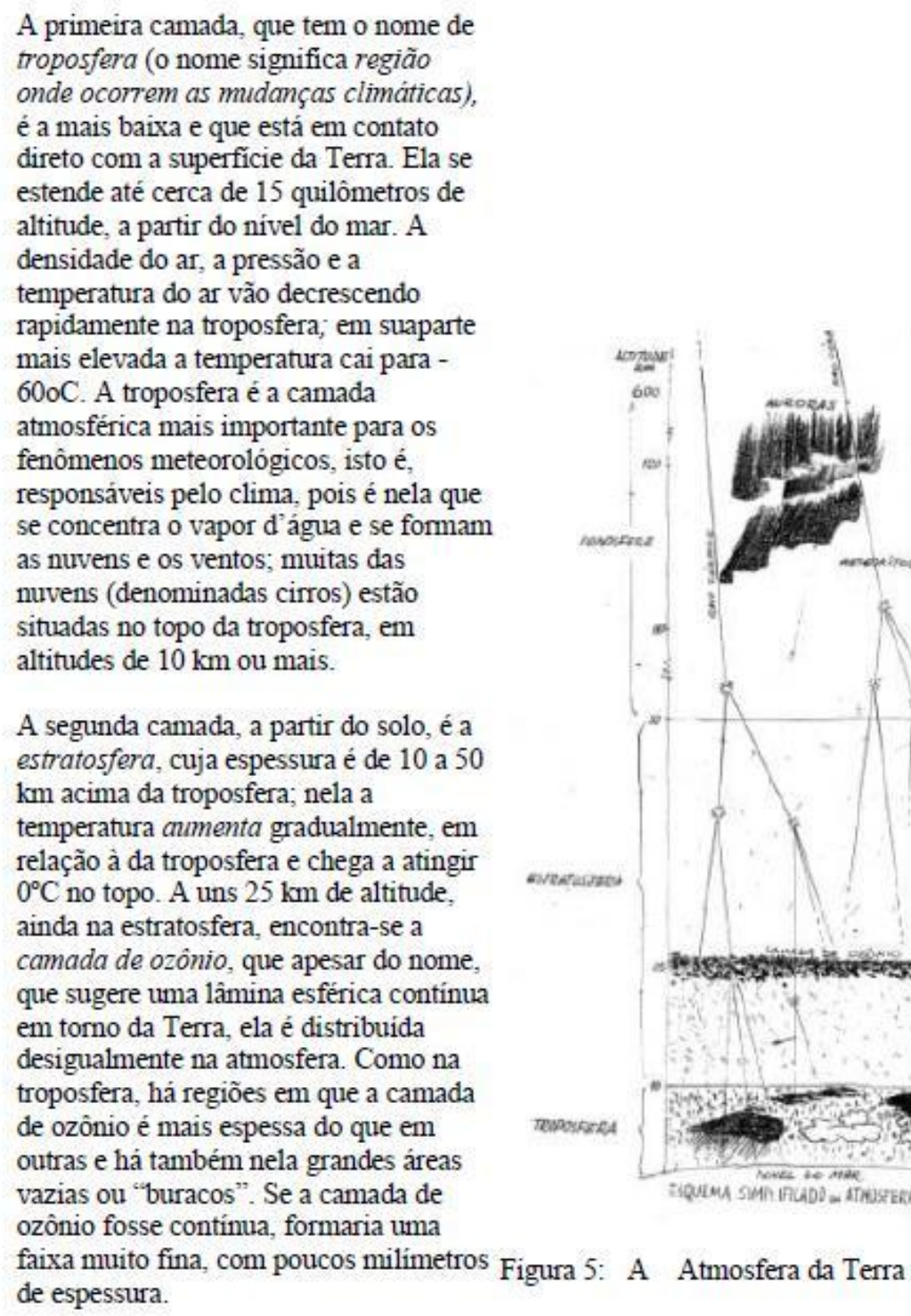

Figura 5: A Atmosfera da Terra

Figura 4: Exemplo de explicação que combina imagem e texto: a atmosfera da Terra (MD3)

Não é apenas por meio de esquemas e diagramas que as explicações estão presentes nos textos didáticos do CBC Física. Encontramos em nosso corpus de análise alguns exemplos de texto escrito que são apresentados abaixo. No exemplo 6 observamos uma explicação de processos que acontecem utilizando a energia solar, como forma de produção e/ou obtenção de outras fontes de energia. 
Ex. 6: (...) as fontes de energia são, em última instância, derivadas da energia do Sol. É a partir da energia do Sol que se dá a evaporação, origem do ciclo das águas, que possibilita o represamento e a conseqüente geração de eletricidade (hidroeletricidade). A radiação solar também induz a circulação atmosférica em larga escala, causando os ventos. Petróleo, carvão e gás natural foram gerados a partir de resíduos de plantas e animais que, originalmente, obtiveram a energia necessária ao seu desenvolvimento, da radiação solar. (RA2 - item Descrição dos procedimentos)

Encontramos também outros exemplos de explicações que detalham processos científicos como, por exemplo, a origem de um combustível fóssil e a destilação da água (exemplos 7 e 8 , respectivamente).

Ex. 7: Esses combustíveis foram todos originados pela ação da energia proveniente do Sol, ao longo da existência de nosso planeta, cuja idade provável é de 4,5 bilhões de anos $\left(4,5 \times 10^{9}\right.$ anos). O processo de formação dos combustíveis fósseis, em linhas gerais, pode ser compreendido lembrando que os animais se alimentam de plantas ou de outros animais que comem plantas. Ora, a vida dos vegetais depende estritamente da radiação solar, graças a um processo de enorme importância que neles ocorre, denominado fotossíntese, que consiste na formação de moléculas orgânicas a partir da água e do dióxido de carbono atmosférico, sendo a luz solar a fonte de energia necessária. (MD2 item 5)

Ex. 8: Além de forçar a circulação da água pelas diversas regiões do planeta, a radiação solar ainda é responsável pela destilação da água. A destilação consiste em vaporizar um líquido e em seguida condensar o vapor obtido, o que permite libertá-lo de componentes indesejáveis. As nuvens se formam por destilação da água e pela condensação do seu vapor em nuvens, o que é uma conseqüência da diminuição de sua temperatura em grandes altitudes da atmosfera. A água proveniente dos oceanos não é potável, devido à sua salinidade; nisso reside a importância da destilação, processo que retém o sal marinho, permitindo que a água das precipitações seja potável e possa ser utilizada para uso humano e animal ou nas plantações. (MD3 - item 7)

Outra categoria que nos permite caracterizar o gênero de texto do CBC Física são as biografias. Estas consistem na apresentação da vida pessoal de uma personalidade relacionada a algum aspecto do tema que está sendo abordado naquele tópico. Além disso, podem ser destacados os trabalhos já realizados por um cientista ou um grupo de pesquisa. No corpus de análise foi encontrado apenas um exemplo de biografia: no item 9 do MD1 foi destacada a 
biografia, com um retrato e um breve relato da história, de um político e diplomata brasileiro símbolo dos capitalistas empreendedores brasileiros do século XIX, Irineu Evangelista de Souza, o Visconde Mauá ${ }^{1}$ como ficou conhecido (ver Ex. 9). Acreditamos que a inserção desta biografia visa atender à própria recomendação da PCF que aponta a importância da relação do conteúdo científico com seus contextos históricos e sociais. Por outro lado, não foi encontrada qualquer biografia sobre físicos ou cientistas que tenham desenvolvido pesquisas relacionadas ao tema energia.

Ex. 9: Irineu Evangelista de Souza (visconde de Mauá) nasceu em Arroio Grande, no Estado do Rio de Janeiro, em 1813, e faleceu em Petrópolis, no mesmo Estado, em 1889. Foi empresário, industrial, banqueiro e político de grande visão, tornando-se pioneiro em várias áreas da economia brasileira. Uma de suas maiores realizações foi ter empreendido a construção da primeira ferrovia brasileira, a Estrada de Ferro Mauá, no Estado do Rio de Janeiro, inaugurada em abril de 1854 (dois anos e meio antes de ser inaugurada a primeira ferrovia em Portuga!!). De origem humilde, sua ascensão social resultou de seus próprios méritos e de suas iniciativas, graças aos quais tornouse um dos homens mais importantes do País em sua época. Foi incompreendido pela sociedade rural e escravocrata em que viveu, mas atualmente é considerado o símbolo dos empreendedores brasileiros do século 19. Foi precursor da valorização da mão-de-obra, do investimento em tecnologia, das transnacionais brasileiras, da globalização, do multi-lateralismo e pioneiro no que veio a ser o atual Mercosul. Modesto, só conhecemos sua biografia graças à exposição de motivos que apresentou aos credores e ao público em 1887, ano em que faliu. (MD1 - item 9)

Em outra categoria analisamos os experimentos os quais geralmente se remetem a procedimentos científicos e que permitem aos alunos compreenderem aspectos relacionados à natureza da ciência. Os experimentos são divididos em dois grupos: no primeiro, os autores do texto didático fazem referência a experimentos realizados por cientistas e, no segundo, são apresentadas atividades experimentais destinadas aos estudantes. Em nossas análises não localizamos qualquer exemplo do primeiro grupo.

Com relação ao segundo grupo, destacamos os textos dos roteiros didáticos uma vez que neste material estão postos três experimentos para os alunos executarem. O primeiro deles, denominado Atividade 1, propõe aos alunos a construção de um modelo com materiais simples e de baixo custo como cartolina, agulha, folha branca e uma moeda (ver Ex. 10). Essa experiência está diretamente relacionada ao assunto apresentado no MD3, item 4. Neste item está presente a

\footnotetext{
1 Informações do sítio: http://www.netsaber.com.br/biografias/ver_biografia_c_2298.html. Consulta em 04 de junho de 2010.
}

R. B. E. C. T., vol 5, núm. 3, set-dez.2012 ISSN - 1982-873X 
mesma figura que representa a distância Terra-Sol, porém no MD3 é identificado e exposto o valor aproximado dessa distância.

\section{Ex. 10: Atividade 01 - Determinando o diâmetro do Sol e o paralelismo dos raios solares (RD3).}

1. Num dia ensolarado pegue uma agulha e faça um furo num pedaço de cartolina e segure-o à luz do Sol. Coloque a folha em branco no solo em outra superfície onde será projetada a imagem. Quando os raios do Sol e a superfície de incidência são perpendiculares, a imagem é um círculo; quando os raios solares fazem um ângulo não-reto com aquela superfície, a imagem é uma elipse.

A) $O$ que acontece com o tamanho da imagem quando a cartolina se distancia da superfície projetada?

2. Coloque uma moeda de 1 centavo de real sobre o papel e faça a imagem solar cair sobre uma moeda, que possui um diâmetro aproximado de $1 \mathrm{~cm}$. Na falta de uma moeda pode-se desenhar um circulo de diâmetro de $1 \mathrm{~cm}$ sobre uma folha no qual se projetará a imagem.

3. Posicione o pedaço de cartolina para que a imagem cubra exatamente a moeda. Esta é uma maneira conveniente para se medir o diâmetro da imagem.

4. Meça a distância entre a cartolina e a moeda ( $h$ ).

5. Determine a razão entre a o diâmetro da imagem (d) e a distância da imagem até a cartolina ( $h$ ).

6. Por semelhança de triângulos $\frac{d}{h}$ deve ser igual a razão entre o diâmetro solar (D) e a distância do Sol à Terra. Usando a informação de que o Sol localiza-se a $150.000 .000 \mathrm{~km}$ de distância da Terra, calcule o diâmetro do Sol.

O diagrama ao lado ilustra a projeção da imagem do Sol por um orifício sobre anteparo horizontal.

De posse do valor do diâmetro do Sol você pode determinar a separação angular máxima entre dois raios luminosos provenientes do Sol que atingem um ponto da superfície terrestre.

7. Encontre a razão entre o diâmetro solar (D) e a distância média da Terra ao Sol.

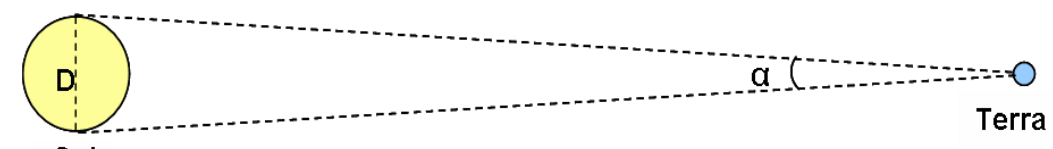

Sol 
8. Essa razão é igual ao ângulo $\alpha$ e será dada em radianos. Podemos transformar o valor de radianos para graus, para isso basta multiplicar a razão encontrada por $57,3 \circ$, pois $1 \mathrm{rad}=57,3$ ․

B) Do ponto de vista prático os raios solares podem ser considerados como paralelos? Justifique.

A seguir reproduzimos o segundo exemplo de experimento presente no RD3. Nele é proposta uma atividade que visa à compreensão da forma como os raios solares atingem a Terra. Essa experiência está diretamente relacionada ao assunto apresentado no MD3.

\section{Ex. 11: Atividade 02 - Os raios de luz que atingem a superfície terrestre (RD3).}

9. Acenda a lanterna colocando um tubo de papel na sua "boca" iluminando inicialmente uma folha de papel branca plana sobre uma parede vertical. Desloque a lanterna para cima e para baixo.

C) A área iluminada varia durante o movimento?

10. Agora faça o feixe luminoso da lanterna incidir sobre a bola de isopor na sua parte central; desloque a bola verticalmente.

D) A área iluminada varia ao longo da bola?

E) Para uma Terra esférica a energia solar chega igualmente a todas as regiões?

F) Na região próxima ao equador uma mesma quantidade de luz atinge uma maior, menor ou igual área do que em outras regiões da Terra?

G) Quais são fatores que determinam a existência das estações climáticas?

Finalmente, a atividade 3 propõe a construção de um aparato que teria como finalidade fazer com que os alunos compreendessem a divisão do ano em suas quatro estações (Ex. 12).

\section{Ex. 12: Atividade 03 - As estações do ano}

11. Fure diametralmente a bola de isopor de $15 \mathrm{~cm}$ com um arame rígido e em seguida prenda sua extremidade livre ao suporte com haste de ferro. $O$ arame rígido, que representará o eixo da Terra, deve estar inclinado em relação a vertical por volta de 23‥ A semi-esfera superior da bola representará o hemisfério Norte e a inferior o hemisfério Sul.

12. Posicione o retroprojetor ou a lâmpada incandescente com boquilha que representará o

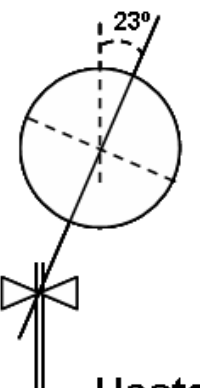

Haste Metálica 
Sol, de modo que a fonte de luz esteja na mesma altura da bola de isopor.

13. Disponha seu modelo de Terra nas quatro posições representadas e veja como as áreas iluminadas variam em cada posição.

H) Identifique na imagem quais as posições que representam o Verão, o Outono, o Inverno e a Primavera.

As exposições são apresentadas como forma de defender uma posição sobre determinado assunto ou também de colocar duas opiniões em debate, geralmente sobre assuntos polêmicos. Foram encontradas poucas passagens com esse tipo de característica definidora do gênero de texto porque nos textos didáticos os conhecimentos científicos são apresentados, com frequência, como produtos de uma ciência neutra, ou seja, como verdades absolutas, não abrindo espaço para o confronto opiniões de especialistas e da população em geral (NASCIMENTO, 2003). No exemplo 13 encontramos a exposição em sua forma sutil, já que o autor se coloca também como responsável pelas alterações causadas ao meio ambiente devido à produção de energia para suprir o aumento populacional. Entendemos que este tipo de exposição constitui-se em uma das possibilidades de apresentação do assunto uma vez que variadas posições poderiam ter sido expostas deixando a cargo do leitor decidir de quem seria essa responsabilidade.

Ex. 13: $O$ aumento mundial do consumo da energia foi de aproximadamente 2,3\% ao ano, a partir de meado do século 19; essa taxa, que é próxima da taxa de aumento populacional. Ela parece muito pequena, mas de fato significou que a cada trinta anos dobrou em nosso planeta o consumo de energia. A evolução desse consumo em todo o mundo tem comprovado que, quanto maior a nossa capacidade para produzir energia, tanto maiores são as alterações que provocamos no meio ambiente. (MD1 - item 4, grifos nossos)

Em outro módulo didático, localizamos uma passagem onde o autor expõe visões distintas sobre o esgotamento dos combustíveis fósseis (ver Ex. 14), não se posicionando com relação a uma delas e adotando uma concepção fatalista e irreversível sobre o assunto.

Ex. 14: Como a Terra e os recursos naturais que existem nela são finitos, está claro que, se continuar o atual ritmo de consumo, as reservas de combustiveis fósseis fatalmente se esgotarão. Prevê-se que esse esgotamento ocorrerá dentro de 30 anos (segundo os pessimistas) ou no máximo em 60 anos (opinião dos otimistas), mas é inevitável. (MD2 - item 8, grifos nossos)

Em outro momento do texto os autores apresentam, em um tom de crítica, os valores de verbas públicas gastas para a construção das usinas nucleares em Angra dos Reis, Rio de Janeiro (Ex. 15). Aqui os autores expõem sua opinião, porém restringe-se a uma dimensão meramente 
econômica deixando de discutir aspectos sociais e impactos ambientais relevantes que dizem respeito ao funcionamento de usinas nucleares.

Ex. 15: Em nosso País existem atualmente em operação duas usinas de geração nuclear (Angra I e Angra II), em 1985 e 2000, respectivamente. Em 1986 o governo brasileiro adquiriu $45 \%$ dos equipamentos para uma terceira usina nuclear (Angra III) e comprometeu-se a adquirir os equipamentos restantes, que custariam 750 milhões de dólares. O armazenamento e a manutenção dessa aparelhagem custam ao povo brasileiro, desde 1986, mais de 20 milhões de dólares por ano, sem falar nos custos financeiros! Isto significa que já desperdiçamos mais de 400 milhões de dólares para manter encaixotada e presumivelmente em bom estado grande parte de uma usina nuclear; além disso, se hoje fosse decidido construir essa usina, seriam necessários pelo menos oito anos de trabalho e gastar mais 1 bilhão e 800 milhões de dólares para colocá-la em operação. (MD2 - item 6, grifos nossos)

A última categoria analisada referente às características definidoras do gênero de texto do CBC Física são as narrativas. Estas se constituem em fragmentos do texto onde os autores apresentam conceitos e processos científicos em forma de estória a partir das quais os alunos podem exercitar a sua imaginação. Em todo o corpus de análise não foram localizadas narrativas desse tipo. No entanto, encontramos em um dos exercícios do MD2 um exemplo de narrativa que não envolve a elaboração do conceito de energia:

Ex. 16: Uma das lendas sobre o xadrez é que seu inventor pediu como recompensa o número de grãos de trigo calculado assim: na 1a casa seria colocado 1 grão, na 2모 dois grãos, na terceira 4 grãos, e assim sucessivamente, dobrando o número de grãos de uma casa à seguinte, até à última casa, a 64무; o número de grãos correspondente a essa casa seria a recompensa desejada. Calcule quantos grãos o inventor receberia. Suponha que cada grão de trigo "pese" 0,001 grama e compare a quantidade de trigo da 64a casa com a produção anual de trigo no mundo (para isso, consulte alguma enciclopédia ou outra fonte dessa informação). Quanto tempo seria necessário para atender ao pedido do inventor do xadrez? (MD2 - Exercício 9)

Entendemos que o exercício acima representa um componente tradicional de livros didáticos de física que enfatizam os cálculos matemáticos deixando de priorizar as dimensões conceitual e cultural da Física. Nesse sentido, os módulos didáticos do CBC guardam maior proximidade do gênero de texto livro didático deixando de adotar uma abordagem inovadora que, em algumas ocasiões, é enunciada no texto do Novo Plano Curricular do Ensino Médio da SEE-MG.

b) Estruturas Textuais

R. B. E. C. T., vol 5, núm. 3, set-dez.2012 ISSN - 1982-873X 
Buscamos complementar a análise lingüística do texto do CBC Física por meio da identificação de dois elementos estruturais: as recapitulações e as metáforas.

As recapitulações consistem em períodos que expõem situações e episódios anteriormente expostos naquele mesmo texto ou em textos anteriores. As recapitulações são próprias do discurso científico escolar, pois fazem uma conexão entre conceitos e conteúdos apresentados em unidades didáticas ou aulas prévias ou, até mesmo, em outras disciplinas escolares. Mortimer e Braga (2003) tratam as recapitulações como retomadas de conteúdos e estabelecimento de diálogo com conhecimentos produzidos em outros contextos, além do próprio conhecimento científico, que acabam por ganhar papel de destaque no cotidiano didático do professor. Identificamos elementos de recapitulação no corpus analisado e apresentamos a seguir alguns exemplos.

Ex. 17: Não se surpreenda, portanto, se no momento você ainda não entendeu o que é energia: você está em boa companhia, a dos físicos, químicos $e$ engenheiros que durante muito tempo lutaram para compreender essa idéia. Vale a pena recordar um argumento apresentado por um físico holandês para mostrar que a energia é algo real: ele nos lembra que em quase todos os países o código penal prevê o furto de energia e estabelece penalidades para quem cometer esse crime (...). (MD2 - item 10, grifos nossos)

Ex. 18: No tópico 2 foi abordada a questão da estrutura interna de nosso planeta e neste módulo foram apresentadas idéias básicas sobre a superfície terrestre. (MD3 - item 8, grifos nossos)

Ex. 19: Não é novidade para ninguém que a água é absolutamente indispensável para a vida e essa questão está se tornando a cada ano mais importante, por causa de várias circunstâncias que afetam diretamente a qualidade e a quantidade de água em nosso planeta.

Uma dessas circunstâncias já foi apontada no estudo do tópico anterior: é a poluição térmica, isto é, o fato de que o funcionamento dos milhões de máquinas térmicas utilizadas pela humanidade está contribuindo aceleradamente, há duzentos anos pelo menos, para o aquecimento da atmosfera terrestre. (MD3 - item 7, grifos nossos)

Ex. 20: Nossa atmosfera, que nos oferece proteção tão variada e importante, está ameaçada e com ela também a vida na Terra. A utilização das inúmeras máquinas térmicas do mundo moderno, como já foi dito contribui poderosamente para o aquecimento ambiental. Mas além do aquecimento elas despejam na atmosfera imensas quantidades de dióxido de carbono $\left(\mathrm{CO}_{2}\right)$ : cerca de 6 bilhões de toneladas por ano! Esse gás está se acumulando nas 
camadas superiores da atmosfera e, conforme já foi explicado, retém parte da radiação solar recebida pela superfície terrestre e por ela devolvida ao espaço, onde deveria se dissipar. Isso provoca uma perturbação no equilíbrio térmico garantido pela atmosfera, cuja temperatura aumenta. (MD3 - item 9, grifos nossos)

Notamos uma particularidade no exemplo 17 no qual os autores fazem a recapitulação de um conhecimento histórico que, não necessariamente, o aluno possa já ter tido contato na escola. Nos demais exemplos (18 a 20), os autores remetem-se especificamente a conteúdos anteriormente abordados no próprio material didático do CBC. Este último tipo de recapitulação é frequentemente utilizado no discurso oral de professores de ciências quando, ao introduzir ou aprofundar um determinado conteúdo, retoma conceitos previamente comentados criando, assim, uma narrativa fundamental para a compreensão e inter-relação de conhecimentos científicos.

A última categoria analisada nos materiais do CBC Física são as metáforas, figuras de linguagem empregadas com a intenção de facilitar a compreensão de determinado conceito por meio da comparação com algo cujo funcionamento ou constituição seja familiar ao leitor. No caso específico do ensino de ciências, as metáforas são utilizadas para aproximar alguns conceitos científicos ao cotidiano dos alunos. Destacamos o fato de que uma metáfora também pode ser entendida como uma comparação abreviada, em que o conectivo comparativo não está expresso, mas subentendido. No nosso corpus de análise encontramos três grupos de metáforas. O primeiro grupo refere-se às metáforas que os próprios autores reconhecem a sua utilização, pois as colocam entre aspas. Abaixo seguem alguns exemplos encontrados nesse grupo.

Ex. 21: O petróleo é (...) encontrado no subsolo, frequentemente a grande profundidade abaixo da superfície, nos interstícios de rochas porosas, não em "poços" subterrâneos. (MD2 - item 5, grifo nosso)

Ex. 22: Nas usinas nucleares o "combustível" é um elemento radioativo, sendo o urânio o mais importante deles para essa finalidade. (MD2 - item 6, grifo nosso)

Ex. 23: O Sol é uma estrela condenada a extinguir-se, pois a radiação que ele produz resulta de ele "queimar" a matéria de que é formado à fantástica taxa de 5 milhões de toneladas por segundo. O tempo de "vida" que Ihe resta, entretanto, é ainda extremamente grande para os padrões humanos: cerca de 5 bilhões de anos; em vista disso, ele pode ser considerado uma fonte renovável de energia. (MD2 - item 8 , grifos nossos)

Ex. 24: $O$ jogo entre o possível e o impossível, que caracteriza a busca por princípios e leis gerais da Física, leva à construção de certas relações tanto 
universais quanto necessárias, relações essas que, uma vez atribuídas aos objetos da realidade permitem a elaboração de modelos explicativos que, supostamente, "reproduzem o comportamento" dessa mesma realidade. (PCF, p.19, grifos nossos)

Ex. 25: Relacionar a Física e a Cultura permite que o aluno compreenda como os conhecimentos desenvolvidos pela Física contribuíram para que nossa civilização modificasse sua visão sobre a constituição e sobre o "funcionamento do mundo". (PCF, p. 19, grifos nossos)

O segundo grupo de metáforas que observamos nos materiais do CBC Física está relacionado à atribuição de características humanas a elementos não vivos (ou processo de antropormofização), e são apresentadas nos exemplos a seguir.

Ex. 26: (...) outros alertam para a necessidade e urgência de aumentar a utilização de energia "limpa", pois é inegável que o uso de certas fontes de energia tem provocado modificações nocivas em nosso planeta. (MD1- item 4, grifo nosso)

Ex. 27: As diversas fontes de energia de que lançamos mão para nossas necessidades podem ser examinadas sob vários critérios. (MD1 - item 7, grifos nossos)

Ex. 28: Sob esse aspecto, o petróleo e o carvão devem ser condenados, pois a queima desses combustíveis tem provocado crescente envenenamento da atmosfera terrestre, onde se acumulam várias substâncias nocivas, originadas dessa queima. (MD1 - item 7, grifos nossos)

O terceiro e último grupo de metáforas refere-se especificamente ao emprego do termo "energia" em outros sentidos que não o científico, conforme observamos no exemplo abaixo.

Ex. 29: Quando lemos no jornal que a autoridade policial agirá com energia contra os assaltos em determinada região da cidade, ninguém confundirá o significado da palavra energia nesse caso com o sentido que ela possui na Física. (MD1 - item 5, grifo nosso)

A partir dos exemplos acima notamos que o domínio conceitual das metáforas presentes no CBC Física encontra-se geralmente relacionado ao cotidiano do aluno, ou seja, os autores buscam no dia a dia dos estudantes objetos, fatos ou características que possam ser relacionados a entidades, processos e sistemas propostos pela Ciência. Essa se constitui em uma característica linguística que expressa concretamente o esforço dos autores em estabelecer relações entre o 
científico e o cotidiano na medida em que incluem explicações que mobilizam entidades destes dois discursos.

\section{Considerações finais}

As análises feitas no presente trabalho tinham como foco a linguagem dos textos que compõem o CBC Física adotados pela grande maioria das escolas da rede pública estadual de Minas Gerais. É importante destacar que não tínhamos como objetivo promover uma análise de conteúdos (tanto daquilo que está presente nos materiais quanto do que se encontra ausente, ou seja, as escolhas de tópicos curriculares pelos autores) tampouco investigar suas abordagens metodológicas. O que pretendíamos era identificar determinados aspectos linguísticos nos textos de modo que pudéssemos caracterizá-lo como um gênero de texto particular que se encontra relacionado à prática social de ensino de física na escola.

Dentre os diferentes gêneros de textos que circulam nas aulas de ciências da rede mineira encontramos os materiais do $C B C$, o qual se constitui, conforme as análises que foram apresentadas, em um gênero de texto didático científico. Segundo Martin (1993), este gênero de texto caracteriza-se pela presença de algumas categorias como os relatos, as explicações, as exposições, as biografias, os experimentos e as narrativas, as quais foram localizadas e exemplificadas por meio da análise linguística aqui realizada.

Nem todas essas categorias foram observadas nos documentos analisados, porém as que localizamos são suficientes para caracterizarmos os textos do $C B C$ como constituintes de um gênero didático. É o caso do relato, que ao longo do material, apresenta-se na forma de classificações e composições por meio das quais os autores expõem novos conceitos os quais aparecem geralmente realçados em itálico à medida que eram inseridos no vocabulário dos alunos. Especificamente na forma de composição, os autores apresentam diagramas e esquemas ao longo dos textos típicos de livros didáticos de ciências. As explicações foram encontradas na forma de exposições de processos científicos em etapas e se diferenciam dos relatos pelo maior número de ações interligadas em uma lógica sequencial ao longo da explicação (algumas vezes representadas por ilustrações).

Outra característica frequente nesse gênero de texto é a apresentação de biografias de cientistas e personalidades relacionadas a algum momento histórico relevante do ponto de vista de desenvolvimento científico e/ou tecnológico. Porém, ao longo de nossa análise, encontramos apenas um exemplo dessa categoria, algo que pode ser indicativo de uma preocupação superficial com aspectos relacionados à história da Física.

O ensino de ciências (e, por conseqüência, seus materiais didáticos) tem sido distinguido das demais disciplinas escolares pela presença sistemática e histórica de atividades experimentais. Em nossa análise, os experimentos foram classificados em duas subcategorias: a primeira diz respeito a experimentos realizados por cientistas e a segunda a experimentos 
sugeridos aos alunos. Não foram encontrados exemplos referentes à primeira subcategoria, o que nos indica que aspectos relacionados à natureza da ciência (neste caso específico à compreensão e à dinâmica da produção do conhecimento científico) deixam de ser incorporados ao texto do CBC. Com isso, ausenta-se uma discussão que ao expor o processo de evolução de determinados experimentos aborda o próprio processo de construção de novos conhecimentos científicos e a evolução da ciência, neste caso a Física. Já na segunda subcategoria foram localizados os roteiros de atividades que são destinados a professores e alunos, propondo a realização de experimentos semelhantes àqueles sugeridos ao final de capítulos de livros didáticos. As abordagens dessas atividades experimentais ainda estão restritas a cálculos matemáticos de modo que o enfoque conceitual torna-se secundário.

Nesse mesmo sentido, o CBC Física anuncia como um de seus objetivos estabelecer uma abordagem menos conceitual e pormenorizada nos três tópicos pertencentes ao Eixo Temático I relacionados à Energia. No entanto, em algumas passagens dos textos analisados principalmente aqueles presentes nos módulos didáticos - os conceitos são abordados de forma ampla sendo omitidos ou chegando, em determinados momentos, a constituírem explicações com erros conceituais os quais têm sido tão criticados e combatidos nos livros didáticos. A aplicação do CBC Física diretamente em sala de aula pode vir a tornar-se deficitária uma vez que ele apresenta em algumas passagens uma superficialidade de conceitos; daí o papel fundamental na formação adequada do professor para saber fazer a mediação deste e de qualquer outro material didático em suas atividades de planejamento e execução de aulas.

Finalmente, entendemos que análises linguísticas de materiais didáticos que circulam nas aulas de física, assim como daqueles com os quais os professores mantêm contato mais próximo para a elaboração de suas aulas, são essenciais para a própria compreensão e uso crítico pelos alunos e docentes. As inovações curriculares e didáticas em várias ocasiões guardam propriedades bastante conservadoras e uma das maneiras que temos de identificar tais movimentos não é apenas pela análise de conteúdos ou métodos didáticos que podem se manter ou se renovar de acordo com a proposta pedagógica do material mas também por uma análise pormenorizada de seus elementos linguísticos. Estes podem nos fornecer pistas com relação não somente à estrutura textual pois a própria seleção de vocábulos, de imagens, da adoção ou não de uma linguagem científica rigorosa que busca uma aproximação superficial com o cotidiano e, assim, acaba por ser descaracterizada, nos dão pistas efetivas acerca das opções e filiações a determinadas correntes filosóficas de educação que são disseminadas em propostas educacionais oficiais. 


\section{Referências}

BARROS, Diana L. P. Contribuições de Bakhtin às teorias do discurso. In: BRAIT, Beth (Org.). Bakhtin: dialogismo e construção do sentido. Campinas, SP: Editora da UNICAMP, 1997.

BRASIL. Lei no 9.394, de 20 de dezembro de 1996. Lei de Diretrizes e Bases da Educação Nacional. Diário Oficial da União, de 23 de dezembro de 1996.

Ministério da Educação. Secretaria da Educação Média e Tecnológica. Parâmetros Curriculares Nacionais: Ensino Médio. Brasília: MEC/SEF, 1999, 360 p.

- Secretaria da Educação Média e Tecnológica. PCN+ Ensino Médio: Orientações Educacionais complementares aos Parâmetros Curriculares Nacionais. Ciências da natureza, Matemática e suas Tecnologias. Brasília: MEC/SEMTEC, 2002, 144 p.

. Ministério da Educação, Secretaria de Educação Básica. Orientações Curriculares para o

Ensino Médio: Ciências da natureza, Matemática e suas Tecnologias. Brasília: MEC/SEB, v. 2, 2006, $135 \mathrm{p}$.

CAUM, Catarine. Análise retórica da Proposta Curricular de Física do estado de Minas Gerais. Trabalho Final de Graduação. Itajubá, MG: DFQ/ICE/UNIFEI, 2010.

CAUM, Catarine e Nascimento, Tatiana G. A Proposta Curricular de Física do Estado de Minas Gerais: uma análise retórica crítica. In: Anais do VIII Encontro Nacional de Pesquisa em Educação em Ciências/I Congreso Iberoamericano de Investigación en Enseñanza de las Ciências. Campinas, SP: ABRAPEC, 2011.

GILL, Ann M. e WHEDBEE, Karen. Rhetoric. In: van DIJK, Teun A. Discourse as structure and process: a multidisciplinary introduction. Vol. 1. London: SAGE, 1997.

HALLIDAY, Michael Alexander K. Some grammatical problems in scientific english. In: HALLIDAY, Michael Alexander K. e MARTIN, James R. Writing science: literacy and discursive power. London: The Falmer Press, 1993.

HALLIDAY, Michael Alexander K. e HASSAN, Ruqaiya. Context of situation. In: Language, context and text: aspects of language in a social-semiotic perspective. Geelong, Victoria: Deakin University Press, 1985.

LIMA, Carlos Henrique da Rocha. Gramática normativa da língua portuguesa: curso médio. 24. ed. Rio de Janeiro: José Olympio, 1984.

LÜDKE, Menga e ANDRÉ, Marli E. D. A. Pesquisa em educação: abordagens qualitativas. São Paulo: EPU, 1986.

MARTIN, James R. Literacy in science: learning to handle text as technology. In: HALLIDAY, Michael Alexander K. e MARTIN, James R. Writing science: literacy and discursive power. London: The Falmer Press, 1993. 
MARTINS, Isabel. Retórica, ciência e ensino de ciências. In: ALMEIDA, Maria José P. M. e SILVA, Henrique César (Orgs.). Linguagens, leituras e ensino da ciência. Campinas, SP: Graf. FE/UNICAMP, 2000.

MARTINS, Isabel e VILLANI, Carlos Eduardo P. Onda ou partícula: argumentação e retórica na aprendizagem da natureza da luz. In: ABIB, Maria Lucia V. dos S. (Org.). Atas do VII Encontro de Pesquisa em Ensino de Física. Florianópolis: SBF, 2000.

MINAS GERAIS. Secretaria do Estado de Educação. Novo Plano Curricular do Ensino Médio. Belo Horizonte: SEE, 2006. $61 \mathrm{p}$.

Secretaria do Estado de Educação. Conteúdo Básico Comum: CBC Física. Belo Horizonte: SEE, 2007. 60 p.

MORTIMER, Eduardo F. Sobre chamas e cristais: a linguagem cotidiana, a linguagem científica e o ensino de ciências. In: CHASSOT, Attico e OLIVEIRA, Renato José (Orgs.). Ciência, ética e cultura na educação. São Leopoldo: Unisinos, 1998.

MORTIMER, Eduardo F. e SCOTT, Philip H. Atividade discursiva nas salas de aula de ciências: uma ferramenta sociocultural para analisar e planejar o ensino. Investigações em Ensino de Ciências, vol. 7, n. 3, 2002. Disponível em http://www.if.ufrgs.br/ienci/?go=artigos\&idEdicao=24. Acesso em 02 de março de 2010.

MORTIMER, Eduardo F. e BRAGA, Selma A. M. Os gêneros de discurso do texto de Biologia dos livros didáticos de Ciências. Revista Brasileira de Pesquisa em Educação em Ciências, vol. 3, n. 3, p. 56-74, 2003. Disponível em http://www.fae.ufmg.br/abrapec/revista/index.html. Acesso em 13 de abril de 2010.

NASCIMENTO, Tatiana Galieta. 0 texto de Genética no livro didático de ciências: uma análise retórica. Dissertação de Mestrado. Rio de Janeiro: NUTES/UFRJ, 2003. 155 p.

NASCIMENTO, Tatiana Galieta e MARTINS, Isabel. O texto de genética no livro didático de ciências: uma análise retórica crítica. Investigações em Ensino de Ciências, vol. 10, n. 2, p. 255278, 2005. Disponível em http://www.if.ufrgs.br/ienci/artigos/Artigo ID131/v10 n2 a2005.pdf. Acesso em 11 de novembro de 2009.

. Elementos composicionais do texto sobre genética no livro didático de ciências. 2009. Alexandria - Revista de Educação em Ciência e Tecnologia. Disponível em http://www.ppgect.ufsc.br/alexandriarevista/numero 1 2009/Tatiana.pdf. Acesso em 02 de março de 2010.

OGBORN, John; KRESS, Gunther; MARTINS, Isabel e McGILLICUDDY, Kieran. Explaining Science in the Classroom. Buckingham: The Open University, 1996. 
Catarine Caum. Licenciada em Física pela Universidade Federal de Itajubá. Mestranda do Programa de Pós-Graduação em Educação Científica e Tecnológica da Universidade Federal de Santa Catarina (UFSC). catinhak1@gmail.com

Tatiana Galieta. Licenciada em Ciências Biológicas pela Universidade Federal do Rio de Janeiro (UFRJ). Mestre em Tecnologia Educacional pelo Núcleo de Tecnologia Educacional para a Saúde (NUTES), UFRJ. Doutora em Educação Científica e Tecnológica pela UFSC. Professora Adjunta da Universidade do Estado do Rio de Janeiro (UERJ) e docente colaboradora do Programa de PósGraduação Educação em Ciências e Saúde do NUTES, UFRJ. tatigalieta@gmail.com 